\title{
The nature of skilled adult reading varies with type of instruction in childhood
}

\author{
G. BRIAN THOMPSON \\ Victoria University of Wellington, Wellington, New Zealand \\ Vincent Connelly \\ Oxford Brookes University, Oxford, England \\ Claire M. Fletcher-FlinN \\ University of Otago, Dunedin, New Zealand \\ AND \\ SHERYL J. HodSON \\ University of Auckland, Auckland, New Zealand
}

\begin{abstract}
Does the type of reading instruction experienced during the initial years at school have any continuing effect on the ways in which adults read words? The question has arisen in current discussions about computational models of mature word-reading processes. We tested predicted continuing effects by comparing matched samples of skilled adult readers of English who had received explicit phonics instruction in childhood and those who had not. In responding to nonwords that can receive alternative legitimate pronunciations, those adults having childhood phonics instruction used more regular grapheme-phoneme correspondences that were context free and used fewer vocabulary-based contextually dependent correspondences than did adults who had no phonics instruction. These differences in regularization of naming responses also extended to some low-frequency words. This apparent cognitive footprint of childhood phonics instruction is a phenomenon requiring consideration when researchers attempt to model adult word reading and when they select participants to test the models.
\end{abstract}

Psychology Lab A produces data on accuracy levels for the naming of nonwords from a sample of skilled adult readers, but Lab B, using the same stimuli and procedures, produces highly divergent results from another sample matched in age and reading skill. This is not an imaginary illustration. It was our prediction on the basis of (1) knowledge of the divergent types of reading instruction with which the two samples of adults learned to read when they entered elementary school, (2) published research on the differential effects of these types of instruction on children's reading processes, and (3) theory on developmental continuity in reading processes from early childhood to adulthood.

What justifies a prediction of developmental continuity into adulthood of reading processes arising from the type of instruction received in early childhood? Justification comes only from theory, since there is no relevant empirical evidence. In the theory of Ziegler and Goswami (2005), orthographic-phonological units can be of various grain sizes. When children learn to read English, traditional explicit phonics instruction is said to influence them toward use of the smallest grain size, letter-phoneme units, rather than toward larger units. Nevertheless, it is argued that in English orthography, these small grain size correspondences are often inconsistent, and beginning readers have to learn additional correspondences of larger grain size that can offer greater consistency. Continuity of reading processes from childhood to adulthood is a feature of the theory, although there is no reference to continuity of the influence of the type of instruction.

On the other hand, in the influential theory of acquisition of reading skill presented by Share (1995), there is a major shift in cognitive processes beyond the beginner level. There is also the claim that satisfactory progress by beginning readers requires teaching of simple explicit grapheme-phoneme correspondences. Children's processes of mapping orthographic information into phonological information are said to shift from use of these taught letter-sound relationships (predominantly context free) to use of those relationships that children implicitly induce from their acquired reading vocabulary of familiar words, including those relationships dependent on context in words. Share cited as evidence the developmental decline of regularization errors and of the regularity effect that gives a reading performance advantage for words with regular spellings over those with irregular ones. This 
theory, then, implies a major developmental shift rather than continuity. Evidence (V. Coltheart \& Leahy, 1992, 1996; Treiman, Kessler, Zevin, Bick, \& Davis, 2006), nevertheless, suggests that if any such shift occurs, it happens as early as the end of the child's 1st year of school reading instruction.

The explicit form of phonics involves teaching the child to respond to words with sounds for successive individual graphemes. In the 1st year, this teaching makes little reference to how such correspondences can be influenced by context in the word - that is, position in the word and/or the relationship to other graphemes (Connelly, Johnston, $\&$ Thompson, 2001). The knowledge sources theory of acquisition of reading (Fletcher-Flinn \& Thompson, 2004; Thompson \& Fletcher-Flinn, 2006) includes an account of the influences of types of instruction on the processes of reading acquisition and implies developmental continuity from the beginning of instruction. Consistent with this account, there is evidence that phonics teaching has generalized consequences for the way young children process unfamiliar words. When children in their 1st year at school who had received explicit phonics instruction attempted to read new words (nonwords), they used graphemephoneme correspondences without sensitivity to conditional influences of the position of the correspondences in words (Fletcher-Flinn, Shankweiler, \& Frost, 2004). On the other hand, children without explicit phonics showed sensitivity to conditional influences of the position that the correspondences occupied in words in their reading vocabulary (Thompson, Cottrell, \& Fletcher-Flinn, 1996).

Since explicit phonics instruction is designed to assist beginning readers in their attempts at pronunciation of new or unfamiliar print words, developmental continuity in the effects of this instruction should be seen in the skilled adult reader's pronunciation of nonwords (e.g., nush, thild). We predicted for the skilled adult readers that their responses to nonwords would be influenced by the way orthographic-to-phonological mappings had been taught in their initial childhood reading instruction. If this instruction had an emphasis on the child's use of individual grapheme-phoneme correspondences, independently of the grapheme context in words, we predicted that a continuing influence of that instruction into adulthood would be shown by a high incidence of regularizations and a low use of grapheme context or units larger than the grapheme.

Several empirical studies (Andrews \& Scarratt, 1998; V. Coltheart \& Leahy, 1992; Glushko, 1979; Treiman, Kessler, \& Bick, 2003) have examined the type of pronunciations adult readers give to nonwords, by exploiting vowel graphemes of English orthography that are heterophonic, having alternative legitimate pronunciations. It is noted that in these studies, no information was provided on the type of reading instruction experienced by the adult participants. All the studies used nonwords to which the reader could give a legitimate pronunciation response that was either (1) regular (e.g., thild, with the vowel pronounced as in fill), having the phoneme that most commonly corresponds to the individual vowel grapheme, independently of the grapheme context in the nonword (i.e., regular in context-free grapheme-phoneme correspondence), or (2) body-consistent irregular (e.g., thild, with the vowel pronounced as in child), with the pronunciation consistently conditional on the grapheme context (e.g., $-l d$ ) in the nonword. In research on reading processes, the vowel grapheme and following consonant grapheme (or consonant grapheme cluster) of a syllable have often been described as a multigrapheme vowel-consonant unit, called a word body. Although we use this label here, we are not committed to an explanation in terms of a body unit rather than in terms of the contextual influence of consonant grapheme(s) on pronunciation of the preceding vowel grapheme (Treiman et al., 2003).

Many word-reading research data, including that on nonword pronunciation, have been simulated with some success by current computational models of adult word reading (e.g., M. Coltheart, Rastle, Perry, Langdon, \& Ziegler, 2001; Harm \& Seidenberg, 2004; Plaut, McClelland, Seidenberg, \& Patterson, 1996). It is of some significance whether a model can simulate what readers transfer from past experience of other words, and word components, to their responses to new words (nonwords). The data simulated have been obtained from samples of skilled adult readers without knowledge of their instructional histories, particularly the type of instruction with which they started learning to read. Nevertheless, there has been some recent discussion suggesting that the type of reading instruction experienced in childhood should be a factor to consider in such theoretical models (Harm \& Seidenberg, 2004, pp. 713-714; Treiman et al., 2003, p. 70; Zevin \& Seidenberg, 2006, p. 148).

Andrews and Scarratt (1998) collected data from skilled adult readers on their specific alternative pronunciations of sets of monosyllabic nonwords containing heterophonic vowel graphemes and conducted a simulation by the dual-route cascaded (DRC) model (M. Coltheart, Curtis, Atkins, \& Haller, 1993). This model had a bias toward regular, rather than legitimate, body-consistent irregular pronunciations that are consistently conditional on the grapheme context. Zevin and Seidenberg (2006) reported similar findings with the more recent version of the DRC model (M. Coltheart et al., 2001) for a simulation of the same data set. They also found that simulation by a "slightly modified version" of the parallel distributed processing model of Harm and Seidenberg (1999) had a much smaller bias toward regular pronunciations. Treiman et al. (2003) obtained data from skilled adult readers on their specific alternative pronunciations of nonwords representing a small set of heterophonic vowel graphemes. They reported simulations by most current computational models of adult word reading and concluded that none of them provided a good simulation of their data on the incidence of acceptable body-consistent irregular pronunciations. The DRC model (M. Coltheart et al., 2001) had the strongest bias toward regular pronunciations.

The principal aim of our study was to take the empirical research further by determining whether pronunciations of heterophonic nonwords by skilled adult readers were affected by the type of initial school instruction in reading that they had received. The first class of heterophonic non- 
words we examined, such as nush, can yield a pronunciation that is regular and compatible with some word bodies in the reader's vocabulary - such as rush, brush-or is compatible with other word bodies of the reader's vocabulary - such as bush, push - where the correspondence for the vowel grapheme is not the most common and is labeled irregular. These nonwords are described here as regular, body-inconsistent because, in the body, they can receive either a vowel pronunciation that is regular or one that is compatible with a body having a pronunciation that is irregular in grapheme-phoneme correspondences. Explicit phonics instruction for school beginners emphasizes regular individual grapheme-phoneme correspondences much more than pronunciation of word bodies. If there were developmental continuity in the effects of explicit phonics, we would predict that adults with this childhood instruction would make more regular pronunciations for these regular, body-inconsistent nonwords than would adults without this childhood instruction.

The word bodies in the second class of heterophonic nonwords we examined - for example, thild - are pronounced irregularly in words, as in child, mild, and so forth. These bodies are pronounced the same in all (or nearly all) of the reader's vocabulary. Hence, these nonwords are described as irregular, body-consistent. For them, the reader's application of knowledge of the body as a component of real words will result in a body-consistent irregular pronunciation response - for example, thild with the vowel pronounced as in child. On the other hand, if the reader used little of this knowledge and made more use of regular (context-free) grapheme-phoneme correspondences, there would be more regular pronunciations, such as thild with the vowel pronounced using the most common context-free grapheme-phoneme correspondence, as pronounced in $i s$. This result has been obtained for children in their 2 nd year of schooling with explicit phonics instruction, in contrast with a much lower incidence of regular pronunciations among a matched sample who had received less instruction time on explicit phonics (Deavers, Solity, \& Kerfoot, 2000). If there were developmental continuity in the effects of childhood phonics, adults who had received this form of instruction would make many regularizations (responses regular in grapheme-phoneme correspondences) to these irregular, body-consistent nonwords. On the other hand, regularizations would be less likely to occur if the readers made full use of knowledge of word bodies from their reading vocabulary. Hence, we predicted that an initial instructional emphasis on regular grapheme-phoneme correspondences in childhood would be a constraint against the readers' subsequent use of word body knowledge in adulthood. We also predicted that without this childhood instructional emphasis, adult readers would make more use of irregular responses to irregular, body-consistent nonwords.

We also examined other potential long-term residuals of explicit phonics instruction: knowledge of phonics sounds for letters, sounds for digraphs, and awareness of phonemes and graphophonemic units. The sound initially taught in explicit phonics instruction for each letter is the one considered to most commonly correspond to the let- ter. Where explicit phonics is not taught in childhood, it may seem inevitable that adult readers' knowledge of the phonics sounds for individual letters will be inferior. It has been reported, however, that children who were without explicit phonics instruction had near ceiling accuracy in giving phonics sounds for the subset of the letters $b, d, j, k$, $p, t, v$, and $z$, but were significantly lower in accuracy for the remaining letters (Fletcher-Flinn \& Thompson, 2004; Thompson, Fletcher-Flinn, \& Cottrell, 1999). It was shown that this subset of letters was that from which the children could infer the phonics sound of the letter from the initial pronunciation element (e.g., /b/) of the letter name (e.g., /bee/) that was well known to them. This inference has been known as use of the letter-name acrophonic principle. This, however, was not the only source of knowledge of the sounds of letters for children without explicit phonics instruction. In the 1st year at school, such children acquired implicit knowledge of letter-sound relationships from the initial letter position of the words in their reading vocabulary, but for the vowel letters, this source of knowledge was highly variable and unreliable (Thompson et al., 1999). If there were developmental continuity, low levels of correct phonics sounds for vowel letters would be predicted for adults without childhood phonics, as well as the effects of the letter-name acrophonic principle on the subset of consonant letters.

In English orthography, two-letter graphemes (e.g., ch, ai), also known as digraphs, are common. In explicit phonics instruction, the phonics sounds assigned to individual letters are taught first, and it is several months later before explicit instruction on most of the digraphs commences. In contrast to the situation for sounds for individual letters, there are no research data about the influences in childhood on the task of pronouncing isolated digraphs. Although we had no prior research basis for predictions about this variable, we included it.

Children's acquisition of an awareness of the phonemes of heard words is associated with their initial learning of an alphabetic orthography (see the review by Defior, 2004). If a sample consists of participants who learned initially with explicit phonics instruction that strongly emphasized the phoneme corresponding to each grapheme, awareness of that phonological unit would be predicted to be prominent to a greater extent than for those who learned without phonics. Connelly et al. (2001) have reported such a comparative result for samples of children of equal wordreading attainment in their 2 nd year at school. If there is developmental continuity, awareness of phoneme units would be predicted to show a similar pattern of effects in adulthood. Similar predictions may also extend to awareness of graphophonemic units (Scarborough, Ehri, Olson, \& Fowler, 1998).

\section{METHOD}

\section{Design of Sample Comparison}

The participants were drawn from the student populations of two universities and were equated on individual differences in wordreading ability. They were matched on a measure of word reading (vocabulary) that involved the participant's lexical-semantic knowledge, as well as knowledge of the print form of words and 
orthographic-phonological relations. There was, therefore, the concern that equivalent performance on this measure did not necessarily represent an equivalent level of print word and orthographicphonological knowledge for word reading. After the samples were matched on the measure of reading vocabulary, they were administered a word-naming reaction time (RT) task that required only a word pronunciation response and not lexical-semantic identification.

From a different perspective, it might be considered that since the main predictions were about the relative incidence of two types of pronunciation responses to nonwords, the two samples should have been matched on the levels of the participants' total accuracy of responses to the nonword tasks. However, to select participants so that this match was provided could have introduced a confound with the main dependent variable, which would have biased the outcome. For example, it could have excluded the possible outcome that those participants without phonics instruction were less accurate than those with phonics at pronouncing print nonwords in any acceptable way at all.

\section{Participants}

The participants were 52 adults, all of whom were monolingual speakers of English and skilled readers of English. Half consisted of a sample who had been taught reading with explicit phonics in the 1 st year of school. This sample was obtained from the student population of the University of Dundee, Scotland. The other half, the contrast sample without childhood phonics, was obtained from the University of Auckland, New Zealand. The samples of participants were also selected by using a standardized measure of individual differences in word-reading vocabulary, the Nelson-Denny Reading Test, Form E, Vocabulary (Brown, Bennett, \& Hanna, 1981). This comprised 100 items - for example, "To derogate is to . . . [choice of five print words]"; "Ire refers to ..." The two samples of participants were matched on both means and standard deviations of level of reading vocabulary and on age. The obtained sample with childhood phonics had a mean of 78 of the 100 items correct $(S D=12)$ and a score range of 53-97, and the sample without phonics had a mean of 79 items correct $(S D=12)$ with a range of 55-97. The obtained mean reading vocabulary score of both samples was at the test norm level of United States 4th-year college/university students, and the lowest score (53) at the 2nd-year-level. The sample with phonics had a mean age of 24 years $(S D=6)$, and the sample without phonics a mean age of 25 years $(S D=7)$. There were 20 females in the former and 22 in the latter sample. Both samples were made up of undergraduates, and the mean level of university study of each was Year 2. None of the participants had studied linguistics or phonetics or had taught phonics.

\section{Instruction Received}

The sample with explicit phonics instruction had attended elementary schools in Dundee and a small number of other areas of Scotland where the schools provided such instruction from the 1 st year. In this, as well as using graded reading books, children were systematically taught explicit phonics routines for reading unfamiliar words. These routines comprised sounding out individual letters and attempts at blending the sounds into words. The sounds initially taught to the children represented the regular (most common) context-free phoneme for each letter (e.g., the letter $a$ was given the sound as in apple.). Subsequently, the sounds of digraphs were taught (e.g., the pair of $e$ letters make the ee sound). The sounds for vowel graphemes with the final $e$ marker (split graphemes) were also taught as rules. Obvious deviations from regular graphemephoneme correspondences were taught as exception words (e.g., could, done). Letter names were taught but received less emphasis than did letter sounds. Such had been the practices in the schools since before the 1960s (see, e.g., Elder, 1971). The practices represent the strong explicit phonics end of an instructional continuum.

Our comparison sample with no explicit phonics represented the opposite end of the continuum. This sample had attended el- ementary schools in New Zealand, where, by the middle of the 20th century, the teaching of reading had deviated from the traditional phonics approaches that continued in many areas of Scotland. Despite this continued divergence of teaching approaches, a comparison (Mullis, Martin, Gonzalez, \& Kennedy, 2003) of reading comprehension attainments of national samples of children aged 9-10 years, who would have commenced school in 1995-1996, showed that Scotland and New Zealand had equal mean scores. (No comparison is available for children commencing in the 1980s, the decade that would match the time most of our participants commenced school.) Although Scotland and New Zealand are about as far apart as is geographically possible, this distance in no way predicts the extent of variation in culture and education between the countries. The history of settlement of New Zealand by people of literate cultures has been largely one of migration from the United Kingdom, including Scotland. In general culture and education, the two countries share similar values and have a similar structure of universal elementary and postelementary schooling. In the two countries, the average ages of entry into elementary school and introduction to the teaching of reading are similar: 5 years 2 months for Scotland and 5 years 0 months for New Zealand. Each country has its established system for teacher education and monitoring of teaching practice. These constrain the within-country variation in instructional practices among teachers.

In New Zealand, "book experience" (Thompson, 1993) was the established practice for initial teaching of reading throughout the country by the 1970 s. The children read many story texts, progressing through finely graded individualized reading levels. In guiding this reading, the teacher demonstrated to the children the use of sentence or story context and initial letters of words as cues to unfamiliar words and sometimes demonstrated comparisons of multiletter word components (including word bodies) shared with other words already known to the children. Explicit phonics was not taught. Letter names were taught but not phonics letter sounds. (Teaching practices have become more varied among some schools in New Zealand since the mid 1990s, but this is beyond the time period in which our participants were in the initial years of elementary school.) All our participants had attended named schools as described for at least the first 4 years of their schooling. Educators of the period in each country confirmed the type of teaching available at the time.

Connelly et al. (2001) have provided detailed observations within classrooms of the contrasting types of reading instruction in Dundee and New Zealand in 1992. These observations were consistent with the descriptions above. The study also included a comparative examination of the children's reading processes. Although the 6-yearolds in these schools were matched on level of word reading, those in Dundee with phonics instruction were superior to those in New Zealand when making regular responses to nonwords - mainly, regular, body-consistent items (Connelly et al., 2001). A similar result was obtained (Johnston \& Thompson, 1989) from comparable samples of the two countries with children 8 years of age, who had commenced school in the 1980s, as had most of the adults in our samples.

\section{Stimuli and Procedures}

Word naming. Low-frequency words were presented in lowercase for word naming, as in Experiment 2 of Strain, Patterson, and Seidenberg (1995). These words were presented before any tasks involving nonwords or letter or digraph sounds. The words comprised four subclasses, listed in Table 1, with 16 words in each. The exception class (e.g., comb, scarce) referred to grapheme-phoneme correspondences of the word that deviated from the regular. In addition, the word had a word body that, among words of the language, was not frequently irregular in these correspondences. Low imageability (e.g., the words truce, scarce) referred to word meanings that have few sensorimotor properties. There has been subsequent investigation and debate about whether the effects labeled imageability did represent that or whether they were due to other confounding variables (e.g., Monaghan \& Ellis, 2002). Although this is an important issue, it is 
Table 1

Comparison of Adults With and Without Childhood Phonics Instruction: Means and Standard Deviations of Reaction Times (in Milliseconds) and Percentage Accuracy in Word Naming

\begin{tabular}{|c|c|c|c|c|c|c|c|c|}
\hline \multirow[b]{3}{*}{ Subclass of Words } & \multicolumn{4}{|c|}{ Reaction Time } & \multicolumn{4}{|c|}{ Accuracy } \\
\hline & \multicolumn{2}{|c|}{$\begin{array}{c}\text { With } \\
\text { Phonics }\end{array}$} & \multicolumn{2}{|c|}{$\begin{array}{l}\text { Without } \\
\text { Phonics }\end{array}$} & \multicolumn{2}{|c|}{$\begin{array}{c}\text { With } \\
\text { Phonics }\end{array}$} & \multicolumn{2}{|c|}{$\begin{array}{l}\text { Without } \\
\text { Phonics }\end{array}$} \\
\hline & $M$ & $S D$ & $M$ & $S D$ & $M$ & $S D$ & $M$ & $S D$ \\
\hline \multicolumn{9}{|l|}{ Regular } \\
\hline High imageability & 561 & 65 & 561 & 79 & 99 & 2.0 & 100 & 0.0 \\
\hline Low imageability & 590 & 102 & 593 & 87 & 100 & 1.2 & 99 & 2.9 \\
\hline \multicolumn{9}{|l|}{ Exception } \\
\hline High imageability & 565 & 70 & 581 & 81 & 98 & 3.6 & 98 & 4.2 \\
\hline Low imageability & 654 & 148 & 642 & 110 & 68 & 10.1 & 83 & 10.2 \\
\hline
\end{tabular}

not crucial to our present objective. Strain et al. (1995) selected the words for participants in southern England, where Southern British English would be a predominant accent. One of our samples used the educated (standard) variants of the Scottish English accent (StuartSmith, 2004), and the other, the educated New Zealand English accent (Bauer \& Warren, 2004). In scoring the task, two words in each of the exception subclasses were excluded, since one or the other of these accents does not provide a distinction between a correct exception pronunciation and a regularization error.

Other long-term residuals of instruction. The set of three tasks-letter naming, letter sounds, and digraph sounds-which were employed in the studies of Fletcher-Flinn and Thompson (2004), were administered with presentation in lowercase. Each of the 26 letters of the alphabet was presented for naming and then, in a different letter sequence, was presented again for a letter-sound response. In neither letter sequence did any successive letters appear in the standard alphabetic order. Speeded response instructions were given for both. We used this order of the two tasks to make it transparent to the participants (especially important for those without phonics instruction) that letter sounds were different from the preceding letter names. No correction of responses was provided in the tasks. In scoring, correct phonics letter-sound responses were those taught in explicit phonics instruction.

Each of 29 digraphs was presented, and the participants were instructed to say the sound usually made by each sequence of two letters. Speeded response instructions were given. The 29 items were selected on the basis of data published by Berndt, D'Autrechy, and Reggia (1994) and comprised all the bigrams of the print form of the corpus having a frequency of 35 or more among word types, as well as a percentage of instances in which the bigram was a grapheme (corresponds to a phoneme) of $50 \%$ or more. The items were presented in lowercase in the following random sequence: $e e, a w, c h$, $o a, o i, e a, a e, d g, o o, n g, k n, c k, o y, a u, w r, o u, a i, o w, w h, e u, e i, p h$, th, ew, ey, qu, rh, sh, ay. Responses were counted as correct if they matched any of those phonemes that represented $20 \%$ or more of all phonemes corresponding to the digraph in the Berndt, Reggia, and Mitchum (1987) grapheme-to-phoneme analysis of a corpus of correspondences. For several digraphs, this meant that there were two possible correct responses. For example, in the case of the digraph $e i$, the vowel phonemes as in "ceiling" and as in "vein" were both counted as correct.

The phoneme awareness measure was modeled on the classic task (Liberman, Shankweiler, Fisher, \& Carter, 1974) in which (following demonstration items) each of 30 words was presented only in the aural form to the participants, who attempted to count the number of the "smallest sounds" in each-for example, four for socks, five or six for family. The scoring of the acceptable counts took into account the accents of English of both samples of participants. The same words from this task were also used, at least 2 days later, in an extended version of the graphophonemic task (Scarborough et al., 1998) in which the words were presented only in print form. In this task, the partici- pant read and said the word to him-/herself, underlined the letter or letter sequence belonging to each sound in the word, and recorded a count of the number of sounds in the word. This count provided the awareness score of the task, and the underlined letters, the segments' identity score. This order of presentation of the two tasks was employed because it was considered that the aural task would facilitate the appropriate task response set for the following graphophonemic task. An order effect showing this facilitation has been demonstrated for these types of tasks (Lehtonen \& Treiman, 2007).

Nonword pronunciation. The nonword pronunciation tasks each included sets of regular, body-consistent; regular, body-inconsistent; and irregular, body-consistent nonwords presented in a randomized sequence. For the first of these classes of nonwords - for example, stell, dilt-only a regular response was legitimate. The other two classes were heterophonic nonwords, as described earlier. Each nonword was monosyllabic and of a consonant-vowel-consonant form. They were from two sources. The first source was Experiment 2 of Andrews and Scarratt (1998; AS set), which was devised for the reading vocabulary of skilled adults. The second source was Task 2 of V. Coltheart and Leahy (1992; CL set), which was devised for readers as young as 1 st grade. The children near the end of the 1 st grade in their study obtained a mean reading accuracy of $77 \%$ for the most common real words that provided exemplars of the word bodies used in the experimental nonwords. The nonword stimuli were presented as in the original experiments. The stimuli were in lowercase, and the tasks included speed instructions.

Both sets of nonwords had been devised originally for participants with an Australian English accent. Hence, in scoring the two sets, some nonwords had to be excluded for all the participants, due to the failure of the accent of one or the other sample to provide the requisite distinction between regular and body-consistent irregular pronunciations. In the Scottish Standard English accent (StuartSmith, 2004) of one sample of our participants, for example, the members of such pairs as mood and good, or mass and grass, have a common vowel phoneme. See the Appendix for the AS items and the CL items scored. ${ }^{1}$ This appendix includes International Phonetic Alphabet transcriptions for the standard phonological descriptions of the two English accents. The consonant differences between these accents are minor (Bauer \& Warren, 2004; Stuart-Smith, 2004), and none of these differences are involved in the scoring. The vowels of these accents are phonologically different, but what matters here is whether, within the phonological system of each accent, there is the distinction between a regular and a body-consistent irregular pronunciation. ${ }^{2}$ Native speakers of the relevant accent, who had experience in phonemic analysis, scored the participants' pronunciations from audio recordings. All responses to the nonwords that were counted as acceptable were either regular pronunciations or bodyconsistent irregular pronunciations, as set out in Andrews and Scarratt (1998, Experiment 2) and, with one exception, ${ }^{3}$ in V. Coltheart and Leahy (1992, Task 2). As in these studies, all other responses were classified as errors. 


\section{RESULTS}

\section{Word Naming}

Mean naming RTs for correct initial responses to the low-frequency words were obtained (Table 1), following deletion of outlier values. The mean and standard deviation were obtained for each participant, and RTs that were more than three standard deviations from each participant's mean were deleted as outliers. These comprised fewer than $1 \%$ of the correct responses of all the participants. The RTs were analyzed in an ANOVA with three factors: samples of participants (with vs. without childhood phonics), regularity of words (regular vs. exception grapheme-phoneme correspondences of words), and imageability of words (high vs. low). For the naming RTs, the main effect of samples of participants was not significant $[F(1,50)<1]$, and neither were the interactions of the sample effect with the word regularity effect $[F(1,50)<1]$ or with the imageability effect $[F(1,50)<1]$ or the threeway interaction $[F(1,50)=1.50, p>.10]$. The significant main effects of regularity $[F(1,50)=37.51, p<.001]$ and imageability $[F(1,50)=27.68, p<.001]$ were qualified by the significant interaction between these two effects $[F(1,50)=12.21, p<.01]$. Tests of simple contrasts showed that the word regularity effect was significant among the low-imageability words $[F(1,50)=44.42, p<$ $.001]$ but was not significant among the high-imageability words $[F(1,50)=1.99, p>.10]$. The results clearly show that the two samples of participants were equivalent in overall word-naming RTs for the four subclasses of words. Moreover, they showed equivalent interactions of the effects of word regularity and imageability that followed the same pattern that was reported by Strain et al. (1995, Experiment 2) and shown in the replication by Monaghan and Ellis (2002, Experiment 4).

Accuracy levels of the responses to the low-frequency words were matched, although at (or close to) ceiling level for the regular words and the exception high-imageability words (Table 1). In naming words of the exception, lowimageability subclass, the participants with childhood phonics were significantly less accurate than those without in the analysis by participants $\left[F_{1}(1,50)=26.00, p<.001\right.$, $\left.\eta^{2}=.34\right]$, but not in the analysis by items $\left[F_{2}(1,13)=\right.$ $4.35, p>.05]$. Regularizations accounted for most of the errors, with a mean of $21 \%(S D=10 \%)$ of all responses to these words for the participants with childhood phonics and $13 \%(S D=8 \%)$ for the participants without. This difference was significant $\left[F_{1}(1,50)=10.70, p<.01, \eta^{2}=\right.$ $\left..18 ; F_{2}(1,13)=6.45, p<.05\right]$.

\section{Other Long-Term Residuals of Instruction}

The adults with childhood phonics instruction showed higher overall accuracy in giving phonics sounds to letters (Table 2). An item analysis was conducted, in view of the prediction that those participants who did not receive explicit phonics instruction would continue to show effects of their childhood use of the letter-name acrophonic principle in responses to a subset of the consonant letters. The adults without phonics instruction were at ceiling level in their phonics responses to the 8 consonant letters
( $b, d, j, k, p, t, v, z)$ that are compatible with the acrophonic principle, but were significantly inferior to adults with this instruction in providing phonics sounds for the other 13 consonant letters $[F(1,12)=7.11, p<.05$, for the 13 matched pairs of item values] and were much inferior for the 5 vowel letters $[F(1,4)=10.17, p<.05$, for the 5 matched pairs of items]. These results are consistent with the predicted long-term residual effect of childhood use of the letter-name acrophonic principle as a partial substitute for instruction in the phonics sounds of letters. ${ }^{4}$ Letter-name knowledge was at ceiling for both samples of participants. There was not a significant difference between the two samples of participants for their accuracy in giving the sounds for digraphs (Table 2).

For accuracy of awareness of heard phonemes, the sample with childhood phonics was significantly superior to those without. The means, standard deviations, significance levels, and effect sizes are presented in Table 2. In graphophonemic awareness and identity of segments, with the stimulus words presented only in print, there is more opportunity than in phoneme awareness for participants' knowledge of the spelling of the words to influence the results. Despite this, the predicted sample effect of phonics instruction was significant for graphophonemic segment identity, although of an effect size smaller than that for phoneme awareness (Table 2). Graphophonemic awareness showed only a marginally significant difference between the samples.

Although the mean levels of word-reading vocabulary of the two samples were closely matched, it was considered informative to examine whether our participants' reading vocabulary levels were, in fact, associated with any of the accuracy measures among the dependent variables. With this in mind, we conducted standard ANCOVAs with participant's level of word-reading vocabulary as the covariate, as well as the corresponding ANOVAs reported above. Due to the matching of means between samples, it was not expected that ANCOVAs should indicate any but small covariance adjustments. Nonetheless, the ANCOVAs could

Table 2

Comparison of Adults With and Without Childhood Phonics Instruction: Means and Standard Deviations of Percentage of Accurate Responses for Other Long-Term Residuals of Instruction

\begin{tabular}{|c|c|c|c|c|c|c|}
\hline \multirow[b]{2}{*}{ Variable } & \multicolumn{2}{|c|}{$\begin{array}{c}\text { With } \\
\text { Phonics }\end{array}$} & \multicolumn{2}{|c|}{$\begin{array}{l}\text { Without } \\
\text { Phonics }\end{array}$} & \multirow[b]{2}{*}{$F$} & \multirow[b]{2}{*}{$\eta^{2}$} \\
\hline & $M$ & $S D$ & $\bar{M}$ & $S D$ & & \\
\hline \multicolumn{7}{|l|}{ Phonics sounds for letters } \\
\hline Total & 87 & 9 & 75 & 12 & $18.80^{* * *}$ & .27 \\
\hline \multicolumn{7}{|l|}{ Consonant letters } \\
\hline Compatible & 95 & 5 & 98 & 4 & $0.75^{\dagger}$ & - \\
\hline Not compatible & 86 & 16 & 76 & 23 & $7.11^{*}$ & .37 \\
\hline Vowel letters & 78 & 18 & 36 & 24 & $10.17^{*}$ & .72 \\
\hline Sounds for digraphs & 78 & 8 & 73 & 10 & $4.04^{\dagger}$ & .07 \\
\hline Phoneme awareness (aural) & 76 & 16 & 61 & 11 & $14.48^{* * *}$ & .22 \\
\hline Graphophonemic awareness & 74 & 24 & 61 & 20 & $4.68^{*}$ & .09 \\
\hline Graphophonemic segments & 53 & 23 & 39 & 13 & $7.44^{* *}$ & .13 \\
\hline
\end{tabular}

Note $-\eta^{2}$, index of effect size: proportion of participant variance accounted for in the effect. Compatible, compatible with the letter-name acrophonic principle. ${ }^{*} p<.05 .{ }^{* *} p<.01 .{ }^{* * *} p<.001$. †Not significant. 
be critical where ANOVA significance levels were not high. Random assignment of participants was not possible in the comparison of samples made here, and application of the standard linear covariance model for adjustment of means of the dependent variable can be invalid without random assignment. In view of this, it was considered necessary to set a conservative criterion for reliability of differences between samples. Where the covariate is significant, a sample effect will be considered reliable only if both the covariance-adjusted effect and the corresponding unadjusted (ANOVA) effect are significant. This criterion is conservative. For example, a covariance-adjusted effect that is not significant will override a significant unadjusted effect.

In the ANCOVAs for the dependent variables above that comprised the other residuals of instruction, there was only one with a significant effect for the reading vocabulary covariate: accuracy in giving sounds for digraphs $[F(1,49)=9.96, p<.01$, and $r(50)=+.38, p<$ $.01]$. With this covariate adjustment, the sample effect was significant $[F(1,49)=5.41, p<.05]$. However, this difference between the samples was not considered reliable by our criterion, since it was not significant without the covariance adjustment (Table 2).

\section{Andrews and Scarratt (1998) Nonwords}

In the scoring of the nonwords, where a participant gave more than one response to an item, only the final response was scored. Each of the two samples obtained the same mean number of regular (the only acceptable) responses to the regular, body-consistent nonwords of the AS setnamely, 34 of the 37 items that were scored. These nonwords were not heterophonic and, hence, were not our main concern. For the first class of heterophonic nonwords, 32 AS regular, body-inconsistent items were scored. As in the original experiment, acceptable responses were either regular or body-consistent irregular, and other responses were classified as errors. The sample with childhood phonics instruction gave a significantly higher percentage of regular responses than did the sample without phonics $\left[F_{1}(1,50)=27.28, p<.001\right.$; see Table 3 for means, standard deviations, and effect size]. This difference was also significant in the ANOVA by items $\left[F_{2}(1,31)=10.96\right.$, $p<.01]$. On the other hand, the phonics sample gave a significantly lower percentage of body-consistent irregu- lar responses $\left[F_{1}(1,50)=22.29, p<.001 ; F_{2}(1,31)=\right.$ $11.62, p<.01]$. There was not a statistically significant difference between the samples in the percentage of error responses $\left[F_{1}(1,50)=2.94, p>.05 ; F_{2}(1,31)<1\right]$.

For the second class of heterophonic nonwords in the AS set, 40 irregular, body-consistent nonwords were scored. The sample with childhood phonics instruction made a significantly higher percentage of regular responses to these items than did the sample without phonics $\left[F_{1}(1,50)=65.95, p<.001 ; F_{2}(1,38)=41.88, p<\right.$ $.001]$. The phonics sample, on the other hand, made a significantly lower percentage of body-consistent irregular responses $\left[F_{1}(1,50)=22.87, p<.01 ; F_{2}(1,38)=10.88\right.$, $p<.01]$. In the percentage of errors, the samples were not consistently significantly different across analyses both by participants and by items $\left[F_{1}(1,50)=6.45, p<.05\right.$; $\left.F_{2}(1,38)=1.51, p>.10\right]$.

In the ANCOVAs for the AS nonwords, the reading vocabulary covariate was significant for only one accuracy variable, the irregular responses to the irregular, body-consistent nonwords $[F(1,49)=4.75, p<.05]$, but the correlation between this dependent variable and the covariate was not significant $[r(50)=+.27, p>.05]$. The reading vocabulary covariance was significant for two error response variables: errors to the regular, bodyinconsistent nonwords and errors to the irregular, bodyconsistent nonwords. With the covariate adjustments, the sample effects for these three variables showed no change in significance or nonsignificance from that of the unadjusted effects.

\section{Coltheart and Leahy (1992) Nonwords}

Each of the two samples of participants obtained the same mean number of regular (the only acceptable) responses to the regular, body-consistent nonwords of the CL set-namely, 19 of the 20 scored. Apart from one nonword in this class, there was no overlap of scored nonwords between any of the AS and CL sets. In the heterophonic nonwords scored in the CL set, there were 14 regular, body-inconsistent and 12 irregular, body-consistent nonwords. As in the original experiment, acceptable responses were either regular or body-consistent irregular. Other responses were classified as errors. For the first of these two classes of heterophonic nonwords (the regular, body-inconsistent), the sample with childhood phonics in-

Table 3

Comparison of Adults With and Without Childhood Phonics Instruction: Percentage of Regular and Body-Consistent Irregular Reading Responses to Nonwords

\begin{tabular}{|c|c|c|c|c|c|c|c|c|c|c|c|c|c|c|c|}
\hline \multirow[b]{3}{*}{ Set of Nonwords } & \multicolumn{5}{|c|}{ Regular Responses } & \multicolumn{5}{|c|}{$\begin{array}{l}\text { Body-Consistent } \\
\text { Irregular Responses }\end{array}$} & \multicolumn{5}{|c|}{ Error Responses } \\
\hline & \multicolumn{2}{|c|}{$\begin{array}{c}\text { With } \\
\text { Phonics }\end{array}$} & \multicolumn{2}{|c|}{$\begin{array}{l}\text { Without } \\
\text { Phonics }\end{array}$} & \multirow[b]{2}{*}{$\eta^{2}$} & \multicolumn{2}{|c|}{$\begin{array}{c}\text { With } \\
\text { Phonics }\end{array}$} & \multicolumn{2}{|c|}{$\begin{array}{l}\text { Without } \\
\text { Phonics }\end{array}$} & \multirow[b]{2}{*}{$\eta^{2}$} & \multicolumn{2}{|c|}{$\begin{array}{c}\text { With } \\
\text { Phonics }\end{array}$} & \multicolumn{2}{|c|}{$\begin{array}{l}\text { Without } \\
\text { Phonics }\end{array}$} & \multirow[b]{2}{*}{$\eta^{2}$} \\
\hline & $M$ & $S D$ & $M$ & $S D$ & & $M$ & $S D$ & $M$ & $S D$ & & $M$ & $S D$ & $M$ & $S D$ & \\
\hline \multicolumn{16}{|c|}{ Andrews and Scarratt (1998) nonwords } \\
\hline Regular, body-inconsistent & 91 & 4 & 84 & 7 & .35 & 4 & 4 & 10 & 6 & .31 & 5 & 2 & 6 & 5 & .06 \\
\hline Irregular, body-consistent & 42 & 9 & 24 & 7 & .57 & 42 & 9 & 55 & 10 & .31 & 16 & 5 & 21 & 10 & .11 \\
\hline \multicolumn{16}{|c|}{ V. Coltheart and Leahy (1992) nonwords } \\
\hline Regular, body-inconsistent & 84 & 11 & 71 & 13 & .24 & 7 & 11 & 21 & 13 & .26 & 9 & 8 & 8 & 12 & .00 \\
\hline Irregular, body-consistent & 64 & 18 & 28 & 12 & .57 & 28 & 16 & 53 & 15 & .40 & 8 & 7 & 19 & 12 & .23 \\
\hline
\end{tabular}

Note-Regular, regular in grapheme-phoneme correspondences. Irregular, not regular in grapheme-phoneme correspondences. 
struction gave a significantly higher percentage of regular responses than did the sample without phonics $\left[F_{1}(1,50)=\right.$ $15.63, p<.001 ; F_{2}(1,13)=8.94, p<.05$; see Table 3 for means, standard deviations, and effect size]. The sample with phonics gave a significantly lower percentage of body-consistent irregular responses $\left[F_{1}(1,50)=17.14\right.$, $\left.p<.001 ; F_{2}(1,13)=10.12, p<.01\right]$. The samples were not significantly different in the percentages of error responses $\left[F_{1}(1,50)<1 ; F_{2}(1,13)<1\right]$.

For the second class of heterophonic nonwords in the CL set (the irregular, body-consistent), the sample with phonics gave significantly more regular responses than did the sample without $\left[F_{1}(1,50)=70.69, p<.001\right.$; $\left.F_{2}(1,11)=22.67, p<.001\right]$. The phonics sample gave significantly fewer body-consistent irregular responses to the items $\left[F_{1}(1,50)=33.46, p<.001 ; F_{2}(1,11)=8.47, p<\right.$ $.05]$. For these items, the samples were not consistently significantly different in levels of error responses across analyses both by participants and by items $\left[F_{1}(1,50)=\right.$ $\left.15.18, p<.001 ; F_{2}(1,11)=4.49, p>.05\right]$.

In the ANCOVAs for the CL nonwords, the only variable with a significant effect for the reading vocabulary covariate was the error responses to the regular, bodyinconsistent nonwords. With the covariate adjustment, the sample effect for this variable showed no change from the nonsignificance of the unadjusted effect.

\section{DISCUSSION}

The samples of participants were selected in such a way that we could compare those adults who had initially learned to read in schools that taught reading with explicit phonics and those who had been taught without such phonics. The samples had equal levels of both wordreading vocabulary and word-naming RTs. In naming heterophonic nonwords, the adults with instruction in explicit phonics, as compared with those without, gave more regular pronunciation responses and fewer bodyconsistent responses that were irregular in context-free grapheme-phoneme correspondences. All of these differences were statistically significant in analyses both by items and by participants. This was the case for both classes of heterophonic nonwords in both the AS and CL sets. For the irregular, body-consistent nonwords, those adults with childhood phonics instruction gave a much higher percentage of regular responses. In the AS set, 57\% of the participant variance was accounted for in this effect, and the percentage was the same in the CL set (Table 3). The sample differences in percentages of error responses were not consistently significant for either class of nonwords in both the AS and CL sets. These differences in error responses were small relative to the sample differences in the two types of acceptable pronunciations given to the nonwords.

As was predicted, the adults with childhood phonics instruction made more context-free regular pronunciation responses than did the adults without phonics. Moreover, those with phonics made less use of body-consistent pronunciation responses that were irregular in grapheme- phoneme correspondences. Those without phonics did not have the same constraint against use of word-body knowledge that was apparent in those with childhood phonics. In terms of the conceptual framework of Ziegler and Goswami (2005), the adults without childhood phonics instruction used more information from units of a grain size larger than the grapheme. A variant interpretation, not explicitly discussed by Ziegler and Goswami, is that the participants without phonics were more sensitive to the conditional influences of grapheme context on the phoneme correspondences to each grapheme unit. This wordbody information, whether from knowledge of larger units or of conditional influences on the grapheme unit, would derive mainly from exemplars provided in the words of the respondents' reading vocabularies.

These results held for both the AS and CL sets of nonwords. Since the AS set was selected for skilled adult readers, they had word bodies that matched this level of word reading. In contrast, the CL set had word bodies that could be read with high accuracy by children in 1st grade (V. Coltheart \& Leahy, 1992). If the differences between adults with and without phonics in their initial years of schooling had been obtained for the AS set of nonwords, but not for the CL set, developmental continuity from these initial years to adulthood would have been in doubt.

Since the items affected by English accent variation were deleted from the results, an exact linear comparison with the mean response levels reported in the AS and CL articles (Andrews \& Scarratt, 1998, Experiment 2; V. Coltheart \& Leahy, 1992, Task 2) was not possible, but an ordinal comparison was made. For each of the two classes of heterophonic nonwords, in each of the AS and CL item sets, the mean percentage values of the original published results for correct responses were in the range of the pairs of means (Table 3) for our participants with and without childhood phonics. None fell outside the range of these pairs of means for our two samples of participants, for either their regular responses or their bodyconsistent irregular responses. This would be expected if, as we claim, our two samples of adults were selected to represent the opposite ends of a continuum of the extent of experience of explicit phonics instruction. The extent of experience of the AS and CL participants is unknown, except that it would be somewhere on this continuum. For the regular, body-consistent nonwords that were not heterophonic, the original published mean correct response levels, for each of the AS and CL sets, were within 2 percentage points of our values.

The reliable tendency of adults with childhood phonics to make regular responses in naming nonwords was a tendency that extended to the naming of low-frequency words of the exception, low-imageability subclass. The response pattern was one not specific to the demands of the nonword pronunciation task with items for which the participants had no lexical-semantic experience. Nevertheless, it is plausible that the naming responses to some words of this subclass occurred before the participants had accessed any lexical-semantic representation of 
them. The overall accuracy rates for this set of exception, low-imageability words reported by Strain et al. (1995, Experiment 2) and in the replication by Monaghan and Ellis (2002, Experiment 4) were within the range of the pairs of values for our samples of participants with and without childhood phonics. There was no description of the extent of experience of explicit phonics instruction among the participants in the reports of either of these experiments.

As is shown in the covariance and corresponding correlation results, our participants' level of word-reading vocabulary was not reliably associated with their accuracy of regular naming responses to either class of heterophonic nonwords, in either the AS or the CL set, or to the sounds correctly given for individual letters. On the other hand, all these variables were strongly related to the type of reading instruction the participants had received in childhood. These relations were in contrast to those for the participants' accuracy in giving sounds for isolated digraphs, for which the sample difference was not reliably significant. For those participants taught phonics, the sounds for individual letters could continue to have explicit uses for many years afterward-for example, as labels for letters when spelling words. In contrast, the sounds taught for digraphs may have received little or no subsequent use.

Do our results indicate cognitive footprints of the initial years of school instruction, as was predicted, or is it feasible that they represent some confounding with an unrecognized social, cultural, or linguistic factor? Certainly, relative to the original published results, ours are not outliers. We have also presented consistent evidence from other long-term residuals of childhood instruction. As was predicted, the adults with phonics, when compared with those without, had greater awareness of the phonemes of heard words, greater accuracy in graphophonemic segmentation, and greater overall accuracy for the phonics sounds of letters, although following a particular pattern among the letters that had been predicted from previous research with children (FletcherFlinn \& Thompson, 2004; Thompson et al., 1999). In this predicted pattern, the adults without phonics instruction were at ceiling level in giving phonics sounds for the subset of consonant letters compatible with the letter-name acrophonic principle but, in giving phonics sounds for the other letters, were inferior to the performance of the participants with childhood phonics-especially so for the vowel letters.

It is improbable that the total pattern of sample differences can be explained by some confounding factor. If some such nontrivial factor were to be discovered and confirmed, it would also demand attention in the modeling of adult word reading. Nonetheless, as was predicted, the present evidence shows that explicit phonics routines for regular grapheme-phoneme correspondences taught in the initial years of schooling had an effect over almost 2 decades. In the skilled adult readers with this type of childhood instruction, the long-lasting effect consisted of a bias in their reading procedures toward regular responses, when alternative irregular responses based on their reading vocabulary were also relevant. This bias was strong, relative to the responses of our sample of adults not taught explicit phonics in childhood. This developmental continuity survived any shift in the cognitive processes of word reading. If such did occur beyond the beginning level, our results indicate that it was not of sufficient scope to disrupt long-term continuity in the effects of the types of reading instruction examined here. The direct implication of our obtained effects is that when adults attempt to respond to print words not previously encountered, they tend to follow response procedures similar to those learned from their initial reading instruction in childhood.

Our findings are pertinent to recent discussions about whether the type of reading instruction experienced in childhood ought to be included as a factor in computational models of adult word reading. Present models do not include this factor. Zevin and Seidenberg (2006, Figure 3) reported simulations of the original AS data for alternative pronunciations by a "slightly modified version" of the Harm and Seidenberg (1999) model and by the DRC model (M. Coltheart et al., 2001). Both models overestimated the percentage of regular responses to the AS irregular, body-consistent nonwords, the DRC overestimate being larger. In our data, however, the adult sample with childhood phonics, at a mean of $42 \%$ (Table 3 ), is closer than the original AS data to both of these simulation values than is our matched sample without childhood phonics, which has a mean much below, at $24 \%$. Since all current models of the processes of skilled word reading attempt to account for the reading of nonwords, as well as for the reading of words of some familiarity, our findings show the importance of incorporating the type of childhood reading instruction in the models.

The findings also show the relevance of considering long-term effects in the debate on the importance of childhood phonics instruction. In particular, psychological science has claimed to show the cognitive merits of including explicit phonics in reading instruction (National Reading Panel, 2000; Rayner, Foorman, Perfetti, Pesetsky, \& Seidenberg, 2001). It is, then, a surprise to find that no evidence has been available about the effects of such instruction on the cognitive processes of reading in normal adult readers. Our skilled adult readers with explicit phonics in childhood showed a bias in their reading procedures toward regular responses when alternative irregular responses based on word reading knowledge were also relevant. This bias was strong, relative to our matched sample of adults who had not been taught explicit phonics in childhood but had received the "book experience" approach. This includes finely graded individual levels for reading texts and some teacher demonstration of cues to unfamiliar words, such as the initial letter identity and the identity of multiletter word components shared with known words. It is noted that the teaching of explicit phonics based on context-free regular grapheme-phoneme correspondences has been considered an instructional heuristic that is effective for getting children started on reading (Gough \& Hillinger, 1980). However, when children have achieved some read- 
ing skill, do their more mature processes fully supersede those of this instructional heuristic? Our results indicate an answer in the negative. We caution, however, that we are reporting initial findings in a new area of study. Moreover, as in almost all the existing studies of the processes of adult word reading, our participants were highly skilled readers. Hence, we do not know whether less skilled adult readers would show a larger or smaller cognitive footprint from childhood phonics instruction.

\section{AUTHOR NOTE}

This work was supported by the South Bank University (U.K.) Research Development Fund, the University of Auckland (New Zealand) Staff Research Fund, and the University of Auckland Department of Psychology Summer Studentship Fund. We acknowledge with gratitude the contributions of Michelle Duddy, Keith Montgomery, and Alison Arrow. We are indebted to the Test Library, School of Education Studies, Victoria University of Wellington (New Zealand), for provision of test materials. Correspondence concerning this article should be addressed to G. B. Thompson, Faculty of Education, Donald Street, Victoria University of Wellington, P.O. Box 600, Wellington 6140, New Zealand (e-mail: brian .thompson@vuw.ac.nz).

\section{REFERENCES}

ANDREWS, S., \& SCARRATT, D. R. (1998). Rule and analogy mechanisms in reading nonwords: Hough dou peapel rede gnew wirds? Journal of Experimental Psychology: Human Perception \& Performance, 24, 1052-1086.

Bauer, L., \& Warren, P. (2004). New Zealand English: Phonology. In E. W. Schneider, K. Burridge, B. Kortmann, R. Mesthrie, \& C. Upton (Eds.), A handbook of varieties of English: Vol. 1. Phonology (pp. 580602). Berlin: Mouton de Gruyter.

Berndt, R. S., D'Autrechy, C. L., \& RegGia, J. A. (1994). Functional pronunciation units in English words. Journal of Experimental Psychology: Learning, Memory, \& Cognition, 20, 977-991.

Berndt, R. S., Reggia, J. A., \& Mitchum, C. C. (1987). Empirically derived probabilities for grapheme-to-phoneme correspondences in English. Behavior Research Methods, Instruments, \& Computers, 19, 1-9.

Brown, J. I., Bennett, J. M., \& Hanna, G. (1981). Nelson-Denny Reading Test, Form E. Chicago: Riverside.

Coltheart, M., Curtis, B., AtKins, P., \& Haller, M. (1993). Models of reading aloud: Dual-route and parallel-distributed-processing approaches. Psychological Review, 100, 589-608.

Coltheart, M., Rastle, K., Perry, C., Langdon, R., \& Ziegler, J. (2001). DRC: A dual route cascaded model of visual word recognition and reading aloud. Psychological Review, 108, 204-256.

Coltheart, V., \& Leahy, J. (1992). Children's and adults' reading of nonwords: Effects of regularity and consistency. Journal of Experimental Psychology: Learning, Memory, \& Cognition, 18, 718-729.

Coltheart, V., \& Leahy, J. (1996). Procedures used by beginning and skilled readers to read unfamiliar letter strings. Australian Journal of Psychology, 48, 124-129.

Connelly, V., Johnston, R. S., \& Thompson, G. B. (2001). The effects of phonics instruction on the reading comprehension of beginning readers. Reading \& Writing, 14, 423-457.

Deavers, R., Solity, J., \& Kerfoot, S. (2000). The effect of instruction on early nonword reading strategies. Journal of Research in Reading, 23, 267-286.

DEFIOR, S. (2004). Phonological awareness and learning to read: A crosslinguistic perspective. In T. Nunes \& P. Bryant (Eds.), Handbook of children's literacy (pp. 631-649). Dordrecht: Kluwer.

ELDER, R. D. (1971). Oral reading achievement of Scottish and American children. Elementary School Journal, 71, 216-230.

Fletcher-Flinn, C. M., Shankweiler, D., \& Frost, S. J. (2004). Coordination of reading and spelling in early literacy development: An examination of the discrepancy hypothesis. Reading \& Writing, 17, 617-644.

Fletcher-Flinn, C. M., \& Thompson, G. B. (2004). A mechanism of implicit lexicalized phonological recoding used concurrently with underdeveloped explicit letter-sound skills in both precocious and normal reading development. Cognition, 90, 303-335.

GLushko, R. J. (1979). The organization and activation of orthographic knowledge in reading aloud. Journal of Experimental Psychology: Human Perception \& Performance, 5, 674-691.

Gough, P. B., \& Hillinger, M. L. (1980). Learning to read: An unnatural act. Bulletin of the Orton Society, 30, 179-196.

Harm, M. W., \& Seidenberg, M. S. (1999). Phonology, reading, and dyslexia: Insights from connectionist models. Psychological Review, 106, 491-528.

Harm, M. W., \& Seidenberg, M. S. (2004). Computing the meanings of words in reading: Cooperative division of labor between visual and phonological processes. Psychological Review, 111, 662-720.

Johnston, R. S., \& Thompson, G. B. (1989). Is dependence on phonological information in children's reading a product of instructional approach? Journal of Experimental Child Psychology, 48, 131-145.

Lehtonen, A., \& Treiman, R. (2007). Adults' knowledge of phonemeletter relationships is phonology based and flexible. Applied Psycholinguistics, 28, 95-114.

Liberman, I. Y., Shankweiler, D., Fisher, F. W., \& Carter, B. (1974). Explicit syllable and phoneme segmentation in the young child. Journal of Experimental Child Psychology, 18, 201-212.

Monaghan, J., \& Ellis, A. W. (2002). What exactly interacts with spelling-sound consistency in word naming? Journal of Experimental Psychology: Learning, Memory, \& Cognition, 28, 183-206.

Mullis, I. V. S., Martin, M. O., Gonzalez, E. J., \& Kennedy, A. M. (2003). PIRLS 2001 international report. Chestnut Hill, MA: PIRLS International Study Center.

National Reading Panel (2000). Teaching children to read: Reports of the subgroups. Washington, DC: National Institute of Child Health and Human Development.

Plaut, D. C., McClelland, J. L., Seidenberg, M. S., \& PatterSON, K. (1996). Understanding normal and impaired word reading: Computational principles in quasi-regular domains. Psychological Review, 103, 56-115.

Rayner, K., Foorman, B. R., Perfetti, C. A., Pesetsky, D., \& SeidenBERG, M. S. (2001). How psychological science informs the teaching of reading. Psychological Science in the Public Interest, 2, 31-74.

Scarborough, H. S., Ehri, L. C., Olson, R. K., \& Fowler, A. E. (1998). The fate of phonemic awareness beyond the elementary school years. Scientific Studies of Reading, 2, 115-142.

Share, D. L. (1995). Phonological recoding and self-teaching: Sine qua non of reading acquisition. Cognition, $\mathbf{5 5}, 151-218$.

Strain, E., Patterson, K. E., \& Seidenberg, M. S. (1995). Semantic effects in single-word naming. Journal of Experimental Psychology: Learning, Memory, \& Cognition, 21, 1140-1154.

Stuart-Smith, J. (2004). Scottish English: Phonology. In E. W. Schneider, K. Burridge, B. Kortmann, R. Mesthrie, \& C. Upton (Eds.), A handbook of varieties of English: Vol. 1. Phonology (pp. 47-67). Berlin: Mouton de Gruyter.

Thompson, G. B. (1993). Reading instruction for the initial years in New Zealand schools. In G. B. Thompson, W. E. Tunmer, \& T. Nicholson (Eds.), Reading acquisition processes (pp.148-154). Clevedon, U.K.: Multilingual Matters.

Thompson, G. B., Cottrell, D. S., \& Fletcher-Flinn, C. M. (1996). Sublexical orthographic-phonological relations early in the acquisition of reading: The knowledge sources account. Journal of Experimental Child Psychology, 62, 190-222.

Thompson, G. B., \& Fletcher-Flinn, C. M. (2006). Lexicalized implicit learning in reading acquisition: The knowledge sources theory. In C. M. Fletcher-Flinn \& G. M. Haberman (Eds.), Cognition and language: Perspectives from New Zealand (pp. 141-156). Bowen Hills, QLD: Australian Academic Press.

Thompson, G. B., Fletcher-Flinn, C. M., \& Cottrell, D. S. (1999). Learning correspondences between letters and phonemes without explicit instruction. Applied Psycholinguistics, 20, 21-50.

Treiman, R., Kessler, B., \& BicK, S. (2003). Influence of consonantal context on the pronunciation of vowels: A comparison of human readers and computational models. Cognition, 88, 49-78.

Treiman, R., Kessler, B., Zevin, J. D., Bick, S., \& Davis, M. (2006). Influence of consonantal context on the reading of vowels: Evidence from children. Journal of Experimental Child Psychology, 93, 1-24. Zevin, J. D., \& Seidenberg, M. S. (2006). Simulating consistency ef- 
fects and individual differences in nonword naming: A comparison of current models. Journal of Memory \& Language, 54, 145-160.

Ziegler, J. C., \& Goswami, U. (2005). Reading acquisition, developmental dyslexia, and skilled reading across languages: A psycholinguistic grain size theory. Psychological Bulletin, 131, 3-29.

\section{NOTES}

1. The AS nonwords classified as irregular, body-consistent included all the original 24 that Andrews and Scarratt (1998) reported as having a word body that appears in only one real word of English. The irregular, body-consistent class of items also included 16 nonwords with a word body that Andrews and Scarratt reported as appearing in more than one word of the language. In this case, 8 nonwords were excluded in scoring, due to the Scottish accent's not providing the requisite vowel distinction. This left an unbalanced representation of each of these two subclasses of irregular, body-consistent nonwords. Fifty percent of the second subclass had a word body consisting of eign, eigh, igh, or ight, whereas none of the first subclass had any of these. This item selection factor would introduce a confound in attempts to compare the two subclasses. They were, therefore, combined in the results, using unweighted means in the ANOVA.

2. In the CL nonwords classified as irregular, body-consistent, there were two, nold and pold, for which the standard phonological transcriptions (see the Appendix) did not show a distinction for regular and body- consistent irregular pronunciations, but it is noted that there is some uncertainty (Bauer \& Warren, 2004) about what should be the current phonemic classification for this vowel and its variants when followed by $/ 1 /$ in the coda position.

3. The V. Coltheart and Leahy (1992, Task 2) method of item selection and scoring provided, for each nonword, only one acceptable irregular vowel pronunciation consistent with a word body common to several words. In the case of bould and chould, this was the pronunciation of -ould as in the words would, could, and should. However, the pronunciation of -ould as in bold is also consistent with the irregular vowel pronunciation of shoulder, boulder, smoulder, and mould (spelt mold in the U.S. but mould in New Zealand and Scotland, and in Australia, where the CL items originated). Our scoring allowed this as an acceptable response.

4. It may be argued that the adults without phonics instruction would be at much less of a disadvantage in giving sounds for the individual letters if, instead of only the phonics sounds, all sounds that commonly correspond to the letter in English words were accepted as correct. For example, both the sound of the letter $a$ as in ate and the sound as in cat (the phonics sound) were accepted as correct. With this alternative scoring based on the correspondences in English words (Berndt et al., 1987), the participants with childhood phonics remained significantly more accurate in responding with sounds for letters $[F(1,50)=17.26, p<.001$, $\left.\eta^{2}=.26\right]$, at a significance level and effect size almost the same as those obtained by scoring phonics sounds only (Table 2 ).

\section{APPENDIX \\ Nonwords and Pronunciations}

The nonwords are listed in alphabetical order and are followed in parentheses by International Phonetic Alphabet (IPA) transcriptions of exemplar words for the pronunciations of the vowel graphemes. The Scottish Standard English transcriptions are shown first, and the New Zealand transcriptions second. The Scottish IPA transcriptions are in accordance with the system for Scottish Standard English described by Stuart-Smith (2004), and those for New Zealand English in accordance with the system described by Bauer and Warren (2004). See below for the control words for these two vowel transcriptions.

$\mathrm{R}=$ Exemplar word for pronunciation of the vowel grapheme scored as regular. For the two classifications of regular nonwords below, the exemplar word gives the regular pronunciation of the word body of the nonword. However, by definition, that is not possible for irregular, body-consistent nonwords. For these, the exemplar word gives only the pronunciation of the vowel grapheme.

$\mathrm{I}=$ Exemplar word for the pronunciation of the vowel grapheme scored as body-consistent irregular. (For the regular, body-consistent nonwords, by definition, there is no legitimate irregular pronunciation.)

\section{AS Nonwords Scored}

\section{Regular, Body-Consistent}

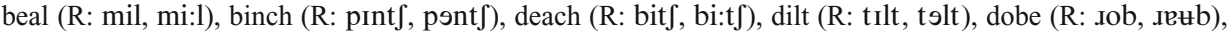



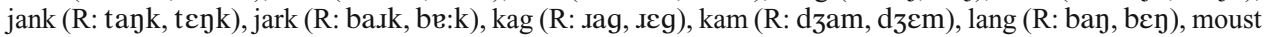

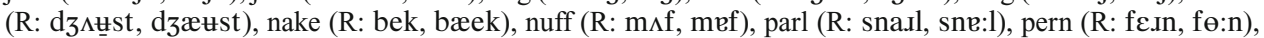

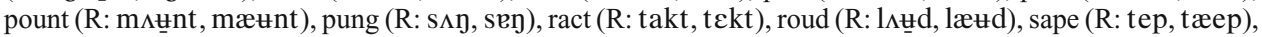

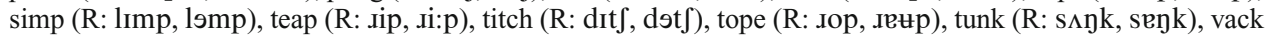
(R: wak, wek), vout (R: lıut, læut), warch (R: matf, me:t $\int$ ), wote (R: vot, veut), yean (R: bin, bi:n), yeech (R: bitf, bi:tf), zill (R: wil, wol).

\section{Regular, Body-Inconsistent}

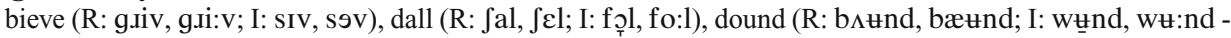

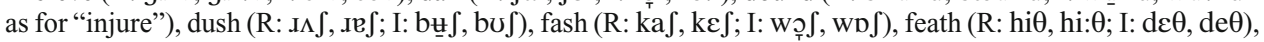
heaf (R: lif, li:f; I: def, def), hild (R: gild, gold; I: wsild, waeld), jamp (R: kamp, kemp; I: swơmp, swpmp), jind (R: wInd, wond - as for "blows"; I: f $\Lambda$ ind, faend), kead (R: bid, bi:d; I: hed, hed), kive (R: dıiv, daev;

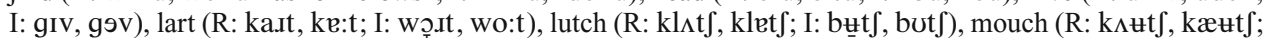

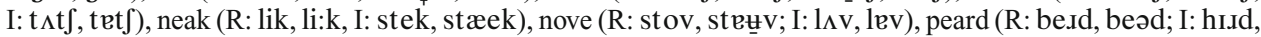

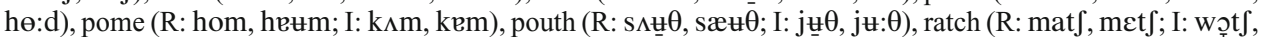

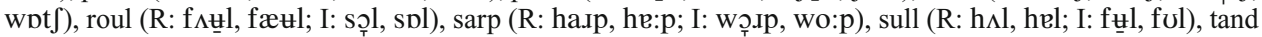

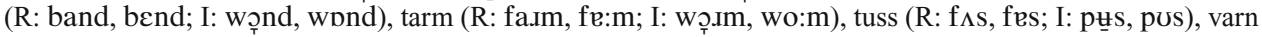

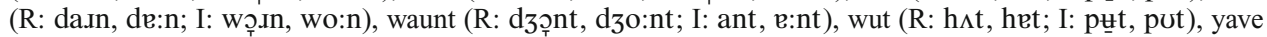
(R: gev, gæev; I: hav, hev), zeat (R: hit, hi:t; I: g.ıet, gıæet or swet, swet). 


\section{APPENDIX (Continued)}

\section{Irregular, Body-Consistent}

bealm (R: bit, bi:t; I: .ılm, .elm), dalt (R: kat, ket; I: mơlt, molt), dinth (R: hit, hэt; I: nıin $\theta$, naen $\theta$ ),

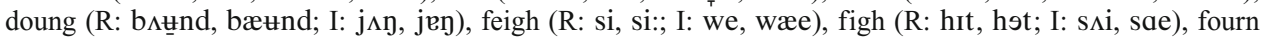
(R: bı

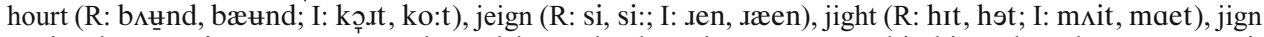

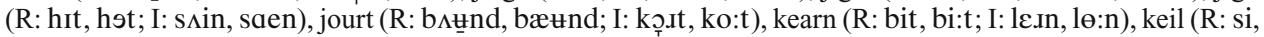

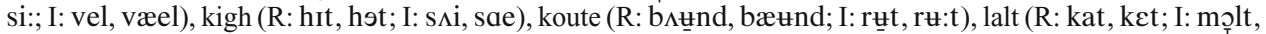

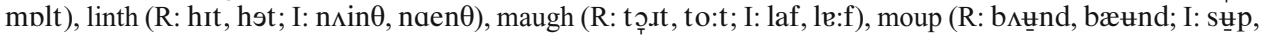

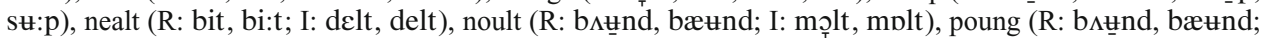

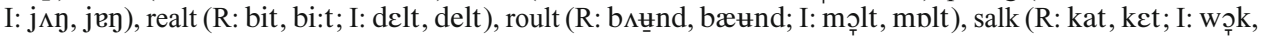

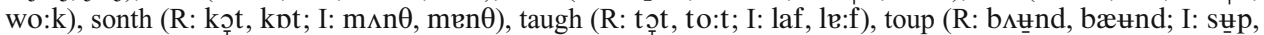

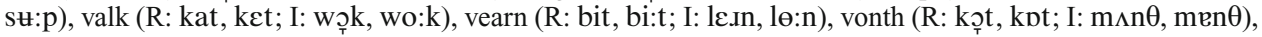

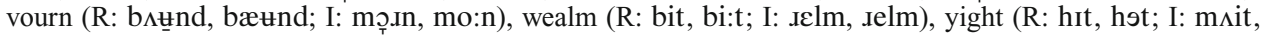
maet), yign (R: hIt, hэt; I: sıin, saen), zeigh (R: si, si:; I: we, wæe), zeil (R: si, si:; I: vel, væel).

\section{Nonwords Scored}

\section{Regular, Body-Consistent}

biss (R: mIs, mэs), chail (R: nel, næel), dack (R: bak, bek), drace (R: fes, fæes), fide (R: hıid, haed), fiss (R: mIs, mэs), fump (R: d3^mp, dzemp), hane (R: ken, kæen), hile (R: f $\wedge$ il, fael), lail (R: nel, næel), ning (R: kıy, kэy), prile (R: f $\wedge$ il, fael), rell (R: wel, wel), stell (R: wel, wel), stide (R: h^id, haed), vack (R: bak, bek), ving (R: kıj, kэy), yane (R: ken, kæen), zace (R: fes, fæes), zump (R: d3^mp, dzemp).

\section{Regular, Body-Inconsistent}

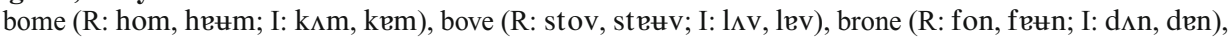

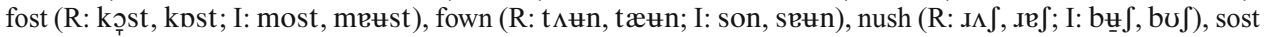

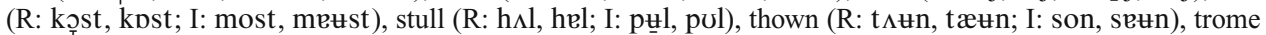

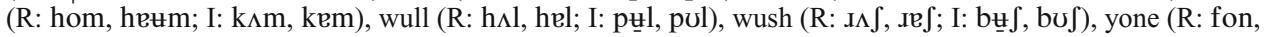
feun; I: d $\Lambda$, den), zove (R: stov, steuv; I: $1 \Lambda v, l e v)$.

\section{Irregular, Body-Consistent}

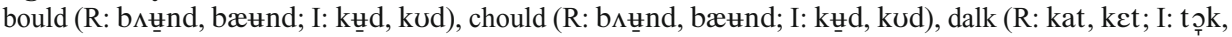
to:k), grall (R: kat, ket; I: tôl, to:l), nalk (R: kat, ket; I: tơk, to:k), nold (R: hơt, hot; I: tôld, told), pold (R: hơt, hot; I: tơld, told), rall (R: kat, ket; I: tọl, to:l), rild (R: hit, hэt; I: whIld, waeld), thild (R: hit, hэt; I: wıIld, waeld), vind (R: hit, hэt; I: kıInd, kaend), zind (R: hit, hэt; I: kıInd, kaend).

\begin{tabular}{|c|c|c|c|c|c|}
\hline \multicolumn{6}{|c|}{$\begin{array}{l}\text { Control Words for Transcriptions of } \\
\text { English Vowel Pronunciations }\end{array}$} \\
\hline Word & $\begin{array}{l}\text { Scottish } \\
\text { Standard }\end{array}$ & $\begin{array}{l}\text { New } \\
\text { Zealand }\end{array}$ & Word & $\begin{array}{l}\text { Scottish } \\
\text { Standard }\end{array}$ & $\begin{array}{c}\text { New } \\
\text { Zealand }\end{array}$ \\
\hline fleece & $\mathrm{i}$ & i: & foot & $\underline{\underline{H}}$ & U \\
\hline bath & $\mathrm{a}$ & $\mathrm{p}:$ & face & $\mathrm{e}^{-}$ & æe \\
\hline birth & I & $\theta:$ & price & $\Lambda$ & ae \\
\hline berth & $\varepsilon$ & $\Theta:$ & prize & $æ$ & ae \\
\hline thought & ? & o: & choice & əe & oe \\
\hline goose & $\underline{\underline{H}}$ & u: & goat & o & $\mathrm{eu}$ \\
\hline kit & $\bar{I}$ & 9 & mouth & $\Lambda \underline{\underline{\Psi}}$ & æ甘 \\
\hline dress & $\varepsilon$ & $\mathrm{e}$ & near & $i^{-}$ & iə \\
\hline trap & $\mathrm{a}$ & $\varepsilon$ & square & $\mathrm{e}$ & eə \\
\hline strut & $\Lambda$ & $p$ & cure & $\mathrm{j} u$ & u \\
\hline lot & $\stackrel{\rho}{\rho}$ & $\mathrm{D}$ & & & \\
\hline
\end{tabular}

